JOURNAL OF THE SOUTH AFRICAN INSTITUTION OF CIVIL ENGINEERING ISSN 1021-2019

Vol 60 No 2, June 2018, Pages 40-52, Paper 1635

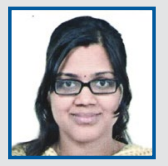

DR SIKSHA SWAROOPA KAR, after graduating in Chemical Engineering, did her M Tech in Material Research Engineering at CSIR-IMMT. She has been working as a scientist at the Central Road Research Institute (CRRI) in the Flexible Pavement Division

for the last five years and completed her PhD on Foaming Technology in this time. Her current research interests include pavement material and design research, low energy mixes using emulsion, rheology of binder and rheology of foamed bitumen, along with design aspects of foamed bitumen.

Contact details:

Academy of Scientific and Innovative Research

Pavement Engineering Area

CSIR - Central Road Research Institute

Delhi-Mathura Road, New Delhi 110025, India

T: +91 112683 2173, E: sikshaswaroopa@gmail.com

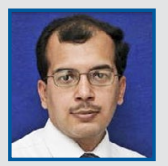

PROF ARAVIND K SWAMY obtained his PhD from the University of New Hampshire, Durham, USA, and then joined the Indian Institute of Technology, Delhi. He has been working as Assistant Professor at IIT, Delhi, for the last seven years and has published more than 30 journal articles. His current research interests include pavement design and modelling, evaluation of pavements, maintenance and rehabilitation of pavements, damage analysis using a continuum approach, rheology, recycling of pavement materials, airport engineering, and systems and optimisation issues in pavement engineering.

Contact details:

Department of Civil Engineering

Indian Institute of Technology Delhi

Hauz Khas, New Delhi 110016, India

T: +91 112659 1191, E: akswamy@civil.iitd.ac.in

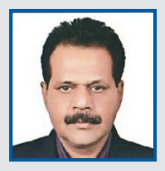

DR DEVESH TIWARI works as Senior Principa Scientist at the CSIR-Central Road Research Institute (CRRI), New Delhi, India. He has published about 85 papers, of which about 25 appeared in renowned journals. He works in the area of highway materials, construction technology and evaluation. His current research interests include flexible pavement design and construction, quality control, maintenance and evaluation, development of pavement management systems and modelling, and pavement failure investigation including technical audits.

\section{Contact details:}

Academy of Scientific and Innovative Research

CSIR - Central Road Research Institute

Delhi-Mathura Road, New Delhi 110025, India

T: +91 112692 1832, E: devesht31@gmail.com

DR P K JAIN retired as Chief Scientist from the CSIR-Central Road Research Institute, after 30 years' service in various administrative posts. He has published more than 50 articles in reputed journals and also delivered about 150 projects as team leader during his tenure. His research interests include pavement materials, pavement stabilisation techniques, low energy mixes using emulsion, and rheology of binder.

\section{Contact details:}

Flexible Pavement Division

CSIR - Central Road Research Institute

Delhi-Mathura Road, New Delhi 110025, India

T: +91 991011 3992, E: pramodj.cri@@ic.in

Keywords: foam bitumen technology, rheology, expansion ratio, half-life

\title{
Impact of low viscosity grade bitumen on foaming characteristics
}

\author{
S S Kar, A K Swamy, D Tiwari, P K Jain
}

The construction of highway infrastructure requires large quantities of construction materials and is an energy-intensive activity. Issues like scarcity of construction materials, increasing cost of materials, increasing cost of construction processes, and the emphasis on less polluting construction procedures have led to advancements in pavement construction practices. One such example is foamed bitumen technology. In this process, cold water is injected into a hot bitumen medium, which leads to drastic expansion of bitumen, forming a fine mist or foam. The performance of foam bitumen mixtures is influenced by the bitumen properties, as well as by the foaming process. This paper deals with research on the rheology of three different types of binders having low viscosity (in the range of 500 to 3000 Poise at $60^{\circ} \mathrm{C}$ ) on foaming characteristics. The water content and temperature also have significant effects on foam decay and the expansion ratio of foam. Results show that a low viscosity bitumen consumes less energy during the foam process compared to high viscosity bitumen. The conclusion drawn from this study is that the expansion ratio and half-life of foam bitumen depend on the rheology of the bitumen, as well as on the chemical composition of the bitumen. It was concluded that, with an increase in carbonyl and sulphoxide compound, the expansion ratio decreases and the half-life increases.

\section{INTRODUCTION}

The increase in road infrastructure around the world and its impact on the environment require serious attention to the development of more sustainable pavement construction. The quest for sustainability in pavement construction constitutes a strong incentive towards the use of cold mix asphalt technology. Foamed asphalt is an attractive cold asphalt mixture, and is becoming an important subject area within sustainable pavement construction practices. It is reported that this mixture has been successfully implemented in many roads across the world, especially in cold recycling.

Foamed bitumen (also known as foamed asphalt or expanded asphalt) is a mixture of air, water and bitumen. When injected with a small quantity of cold water, the hot bitumen expands within an expansion chamber to about fifteen times its original volume and forms a fine mist or foam (Figure 1) (Wirtgen 2004). Foamed bitumen stabilisation (FBS) offers considerable advantages. The use of these mixtures conserves aggregates and bitumen, decreases energy usage, minimises waste and reduces fuel consumption and greenhouse gas emissions. This mixture can therefore significantly reduce the cost of construction (Morton et al 2004). Engineering advantages include the possibility to use a wide variety of aggregates (Morton et al 2002). The foamed binder increases strength when compared to a granular material, exhibiting more flexibility when compared to cement-treated materials, gives faster strength gains compared to cold emulsion mixtures and facilitates possible early opening to traffic (Jenkins et al 2001).

The mechanical properties of FBS depend on the rheological properties of the foamed asphalt binder during production, during construction and when in service. To date the characteristics of foamed bitumen and their effect on mixture properties have not been critically analysed. It is necessary to select the best foam prior to mixing with aggregate materials. This is achieved by investigating the foaming properties of the bitumen. Researchers have reported that the foaming process limits the ageing of the binder and the mixtures (Xiao et al 2013; Martinez-Arguelles et al 2017). In contrast, research by Nivedya et al (2013) indicated that the foamed binder at lower shear rates exhibited viscosity close to the RTFO binder. This necessitates comparing 


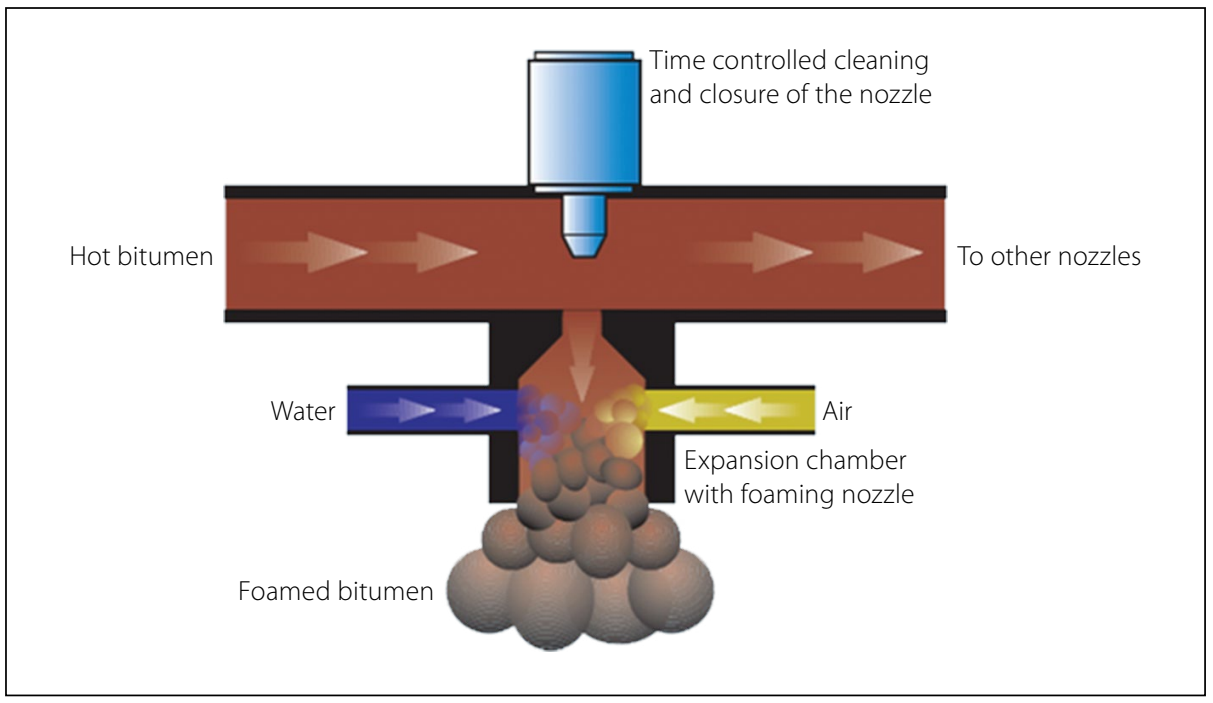

Figure 1 Foamed bitumen production (Wirtgen 2004) the properties of foamed bitumen with that of the short-term aged binder.

It is necessary to investigate the effect of binder composition and binder rheology on foaming characteristics, which will provide a better idea of bitumen-stabilised material behaviour. This paper describes a detailed study related to the effect of binder viscosity on foaming characteristics. It deals with the study of bitumen properties, which includes the ageing parameter prior to foaming and its effect on foaming characteristics. Besides traditional testing (penetration, ring and ball softening point), advanced tests were conducted on bitumen before foaming, using equipment such as the Brookfield rotational viscometer and the dynamic shear rheometer (DSR). Three varieties of asphalt binder with lower viscosity were used in this work.

\section{LITERATURE REVIEW}

\section{Parameters determining characteristics of foam}

The production of effective foam bitumen for pavement recycling applications can be achieved when the base bitumen possesses acceptable characteristics. The main parameters used to determine the quality of the final foamed bitumen product are expansion ratio and half-life. Expansion ratio (ER) is calculated as the ratio of the maximum volume of foam relative measure of the viscosity of the foam and is an indicator of dispersive characteristics. Bowering and Martine (1976) reported that expansion of the foamed bitumen is approximately 15 to 20 times the volume of the original bitumen. The half-life (HL) is measured in seconds and usually lies between 10 and 15 seconds. As the percentage of added water is increased, the HL and ER develop in opposite directions (Asphalt Academy 2009; Sunarjono 2008). Jenkins (2000) developed the concept of a foam index (FI) to measure the combination of expansion ratio and half-life. Saleh (2007) used viscosity of foam also as an indicator of foaming characteristics. Various researchers have indicated that viscosity is a better indicator of foam quality, mixing properties and the workability of FBM. The foam index needs to be analysed in combination with the expansion ratio and the half-life in order to optimise the foaming characteristics of tar for a specified application (Morton 2001). As per Morton to its original volume. ER is an indirect

Table 1 Summary of ER and $\mathrm{HL}$ reported in literature

\begin{tabular}{|c|c|l|}
\hline Half-life (seconds) & Expansion ratio & \multicolumn{1}{c|}{ Reference } \\
\hline$\geq 20$ & 8 to 15 & Ruckel et al (1983) \\
\hline 20 to 45 & 10 to 12 & Lancaster et al (1994); Maccarrone et al (1994) \\
\hline$\geq 7$ & $\geq 7$ & Asphalt Academy (2002) \\
\hline 30 to 45 & $\geq 15$ & Austroads Guide Part 4D (2006) \\
\hline$\geq 6$ & $\geq 8$ & Asphalt Academy (2002) (2009) \\
\hline$\geq 8$ & $\geq 10$ & Wirtgen (2004) \\
\hline
\end{tabular}

et al (2003) optimum foaming results are generally achieved at temperature ranges of $110^{\circ} \mathrm{C}$ and $125^{\circ} \mathrm{C}$, with foamant water content between $1.5 \%$ and $2.5 \%$.

\section{Acceptable range and optimisation of foaming characteristics}

Previous research on foamed bitumen indicated that acceptable values of ER and HL depend on various parameters (Csanyi 1960; Jenkins et al 1999). Accepted minimum values for ER and HL for stabilising material are 10 and 8 respectively (Bowering \& Martin 1976; Asphalt Academy 2009) when the temperature aggregate is between $10-25^{\circ} \mathrm{C}$. When aggregate temperature is higher than $25^{\circ} \mathrm{C}$, the recommended values of ER and HL by various researchers are summarised in Table 1.

\section{Factors affecting foamed bitumen characteristics}

The characteristics of foamed bitumen are highly influenced by various factors like foamant water content, bitumen temperature, viscosity of bitumen, type and composition of bitumen and the temperature of the vessel in which the foamed bitumen is collected (Jenkins \& Van de Ven 2001). Foamed bitumen with a higher expansion ratio and longer half-life has better dispersion through granular materials, resulting in greater strength improvement (Wahhab et al 2012). With increasing water content and temperature, the expansion ratio is expected to increase with a simultaneous decrease in the half-life (Bowering \& Martin 1976; Brennen et al 1983; He $\&$ Wong 2006). This can be attributed to more water availability, and subsequent steam generation. A higher quantity of steam generated leads to the formation of more bubbles. Optimised foamant water content, along with optimum other parameters like air pressure and temperature of bitumen, were established by many researchers (Middleton \& Forfylow 2009; Xiao 2011; Iwánski \& Chomicz-Kowalska 2012). Brennen et al (1983) found that the half-life and expansion ratio of foam were affected by the volume of the foam produced, foamant water content and bitumen temperature at which the foam is produced. According to Nivedya et al (2013), while measuring the apparent viscosity of the foamed binder, the time taken to reach the steady state is independent of the water content and temperature of the foamed binder. 
Table 2 Properties of BEO

\begin{tabular}{|l|l|}
\hline \multicolumn{1}{|c|}{ Properties } & Value \\
\hline Density, d415 & 0.98 \\
\hline${ }^{\circ} \mathrm{API}$ & 11.8 \\
\hline Kinematic viscosity, cSt at $100^{\circ} \mathrm{C}$ & 92.8 \\
\hline Flash point, ${ }^{\circ} \mathrm{C}$ & 242 \\
\hline Asphaltene content, $\%$ wt & 0.62 \\
\hline Aromaticity, (by NMR) & 0.4 \\
\hline Molecular weight (by VPO method) & 660.5 \\
\hline
\end{tabular}

\section{Effect of bitumen viscosity on foam characteristics}

The relationship between the viscosity of foam with respect to time has been developed using a viscometer (Jenkins 2000; Saleh 2007). It is a known fact that the viscosity of bitumen decreases with increase in temperature. The subsequent thinning effect of bitumen on bubbles leads to a reduced half-life. When small bubbles coalesce with larger bubbles, the bitumen film thickness surrounding the bubbles reduces (Saleh 2007; Wirtgen 2004). This reduction in foamed bitumen viscosity leads to a simultaneous decrease in the surface tension in the bitumen film. This in turn leads to excessive steam pressure within the bubbles, leading to the final collapse of the bubbles (Csanyi 1960).

Foamed bitumen produced using lower viscosity (soft grades) bitumen have higher values of expansion ratio and half-life than those produced using higher viscosity (hard grades) bitumen (Abel \& Hines 1979; Raffaelli 2004). However, He and Wong (2006) reported that the bitumen with higher viscosity gave higher maximum expansion ratio compared to those given by lower viscosity bitumen at the same bitumen temperature, air pressure and water content levels. In the case of halflife values, a reverse trend was observed. Half-life was higher for the soft grade bitumen compared to those of a hard grade bitumen. The variation was attributed to differences in viscosity values for the two grades of bitumen. However, it has been found that bitumen of high viscosity produces superior aggregate coating (Abel \& Hines 1979).

\section{Effect of bitumen chemical} composition on foam characteristics Studies by Barinov (1990) illustrated that bitumen containing a higher percentage of asphaltenes lead to a higher expansion

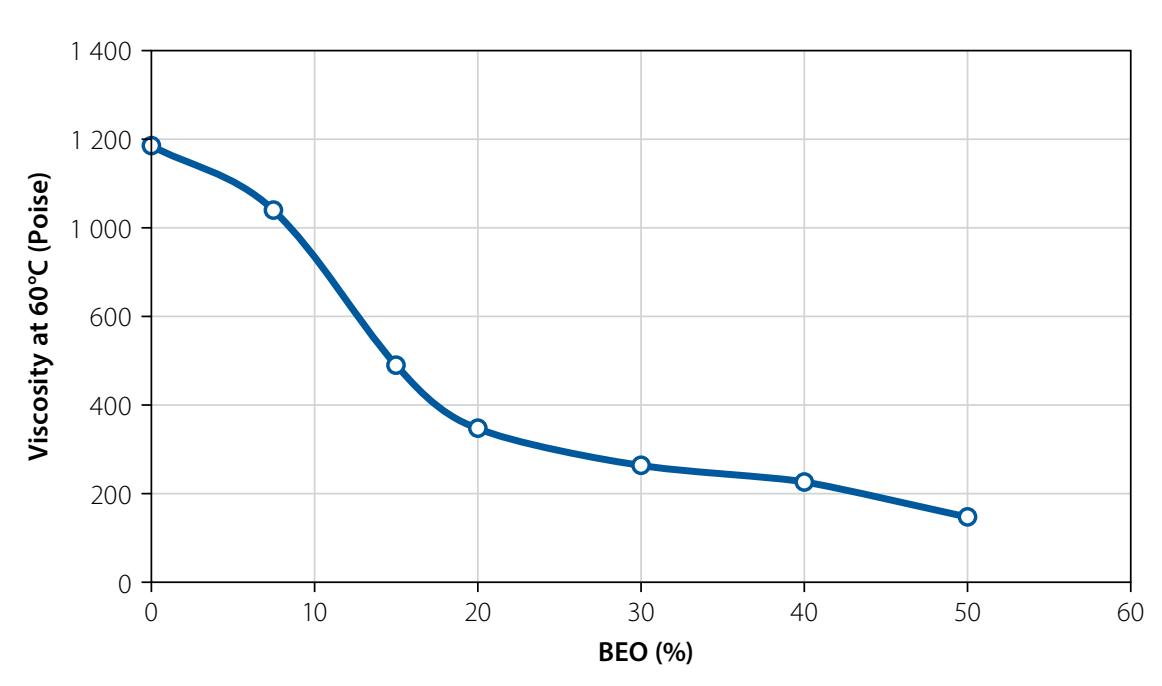

Figure 2 Effect of BEO on VG 10 bitumen

ratio and half-life. This can be attributed to asphaltenes acting as surfactants. While acting as surfactants, asphaltenes reduce the surface tension in the lamellae of the bubbles, as well as the plateau border suction. Thus collapse of the foam is delayed. Crispino et al (2014) studied the foaming properties of chemical modified binder based on oleic acid diethanolamine, showing about 10 times better properties compared to the near binder. Other authors also support this finding (Namutebi et al 2011; Martinez-Arguelles et al 2015). Kendall et al (1999) found that silicones present in the bitumen reduced the foaming ability of bitumen. Thus the presence of silicones necessitates the use of a foaming agent for higher quality foam (Kendall et al 1999). According to Iwánski et al (2015), an increase of wax content up to $2.5 \%$ induced an improvement in bitumen foamability, i.e. increase of expansion ratio and half-life. The effects of binder chemical composition on foaming using Fourier transform infrared spectroscopy and X-Ray radiography techniques have been investigated by various authors
(Namutebi et al 2011; Hailesilassie et al 2015). Lesueur et al (2004) reported that bitumen composition did not influence foaming properties much. Saleh (2007) reported that temperature susceptibility of the binder plays an important role in the foaming process.

\section{EXPERIMENTAL WORK}

\section{Materials}

VG 10 and VG 30 grade bitumen conforming to Indian Standard (1S 2013) produced at the Indian Oil Corporation Limited (IOCL) refinery were used in this study. A typical bitumen extract oil (BEO) was used to reduce the viscosity of the VG 10 bitumen. In this study, lower grade bitumen (LGB) was obtained by blending of VG 10 bitumen and $\mathrm{BEO}$ in a stirrer for $15 \mathrm{~min}$ utes at $150^{\circ} \mathrm{C}$. The physical properties of $\mathrm{BEO}$ used for lowering the viscosity of VG 10 bitumen are given in Table 2. The effect of BEO on the viscosity of VG 10 bitumen is shown in Figure 2. The physical properties of bitumen are given in Table 3 .
Table 3 Properties of LGB, VG 10 and VG 30

\begin{tabular}{|l|c|c|c|}
\hline \multicolumn{1}{|c|}{ Properties } & \multicolumn{3}{|c|}{ Test data } \\
\cline { 2 - 4 } & LGB & VG $\mathbf{1 0}$ & VG 30 \\
\hline Penetration $\left(25^{\circ} \mathrm{C}, 100 \mathrm{~g}, 5 \mathrm{~s}\right), 0.1 \mathrm{~mm}$ & 42.6 & 81 & 47 \\
\hline Softening point (ring and ball), ${ }^{\circ} \mathrm{C}$ & 39 & 44 & 51 \\
\hline Viscosity at $60^{\circ} \mathrm{C}$, Poise & 564 & 1150 & 3230 \\
\hline Viscosity at $135^{\circ} \mathrm{C}, \mathrm{CSt}$ & 225 & 350 & 475 \\
\hline Temperature of $1.01 \mathrm{kPa} \mathrm{G}^{*} / \mathrm{Sin} \delta$ of un-aged bitumen, ${ }^{\circ} \mathrm{C}$ & 60.2 & 66 & 74 \\
\hline Temperature of $2.2 \mathrm{kPa} \mathrm{G} / \mathrm{Sin} \delta$ of $\mathrm{RTFOT}$ residue, ${ }^{\circ} \mathrm{C}$ & 64.0 & 73 & 75 \\
\hline
\end{tabular}




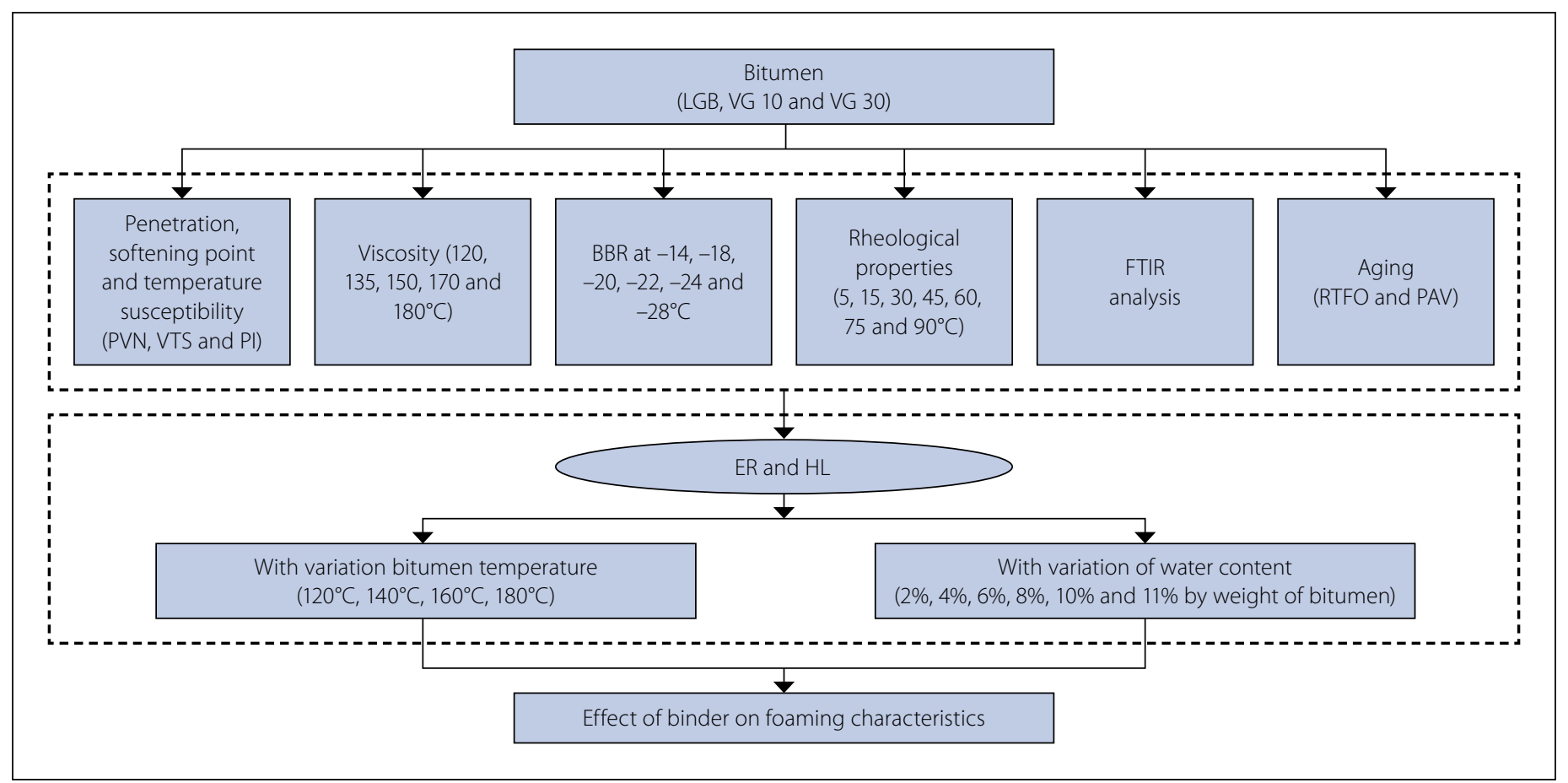

\section{Figure 3 Laboratory experimental study}

\section{Experimental programme}

The experimental study was conducted in two stages, namely:

A. Evaluation of physical and rheological properties of VG 30, VG 10 and low grade bitumen (LGB)

B. Assessment of the foaming properties using foaming pilot plant at laboratory.

The different laboratory tests conducted for these two stages are shown in Figure 3. The tests conducted for Stage A are shown in the upper dotted area and for Stage B in lower dotted area.

\section{Study on the ageing of bitumen}

Ageing is known to be a major phenomenon which influences the performance of bitumen. Many factors contribute to the hardening of bitumen, such as oxidation, volatilisation and polymerisation. The use of bitumen binder as paving material is dependent on its resistance to change in physical properties over the range of temperatures. In general, bitumen ageing takes place in two stages, namely short-term ageing at high temperature during asphalt mixing, storage and laying, and long-term ageing at ambient temperature while in service (seven to ten-year period). Therefore, bitumen (VG 10, VG 30 and LGB) were subjected to ageing by the rolling thin film oven (RTFO) test to simulate its short-term ageing, and the pressure ageing vessel (PAV) test to simulate its long-term ageing. The effects of ageing on the rheological and physical properties of bitumen binders were investigated using the dynamic shear rheometer test (DSR) and the Brookfield viscometer. The ageing index (ratio of viscosity after RTFOT and PAV test to viscosity before RTFOT and PAV test) is one of the most acceptable parameters used to determine the ageing resistance of bitumen.

\section{Rheological test methods}

The viscosity profile of the bitumen was measured using a Brookfield rotational viscometer. The viscosity of VG 10, VG 30 and LGB was measured at $120^{\circ} \mathrm{C}, 135^{\circ} \mathrm{C}$, $150^{\circ} \mathrm{C}, 170^{\circ} \mathrm{C}$ and $180^{\circ} \mathrm{C}$ at a rotational speed of $20 \mathrm{rpm}$.

The viscoelastic response of the bitumen was evaluated using DSR with parallel plate geometry by measuring the complex shear modulus $\left(G^{*}\right)$ and the phase angle $(\delta)$ values. A $25 \mathrm{~mm}$ steel plate was used with a gap width of $1 \mathrm{~mm}$, and measurements were taken at a frequency of $10 \mathrm{rad} / \mathrm{sec}$ with a strain level of $1 \%$. Frequency sweep was conducted in the frequency range of $0.1-25 \mathrm{~Hz}$ at different temperatures $\left(15-90^{\circ} \mathrm{C}\right)$, at an increment of $15^{\circ} \mathrm{C}$. The samples were prepared by pouring the bitumen into silicon moulds with the appropriate geometry for the type of material to be tested.

The bending beam rheometer (BBR) was used to measure the stiffness and the rate of change of stiffness. i.e. the $\mathrm{m}$-value of the binders at low temperatures. The BBR test was carried out as per AASHTO T313 specifications.

\section{Temperature susceptibility determination}

All types of bitumen display temperature dependent properties, i.e. they become softer when heated and hard when cooled. Several equations have been proposed by researchers to relate viscosity (or consistency) with temperature (Airey 2002; Roberts et al 1991). In this study three approaches are used to determine the temperature susceptibility of the LGB, VG 10 and VG 30.

\section{Penetration Index (PI)}

Pfeiffer and Van Doormaal developed an equation for the temperature susceptibility that assumes a value of about zero for road bitumens (Van der Poel 1954). They defined the penetration index (PI) as:

$P I=\frac{20(1-25 A)}{1+50 A}$

Where A is temperature susceptibility and the PI is an unequivocal function of $\mathrm{A}$. If the logarithmic function of penetration $\mathrm{P}$ is plotted against temperature $\mathrm{T}$, a straight line of the following form is obtained:

$\log \mathrm{P}=\mathrm{KT}+\mathrm{A}$

The PI of each bitumen can be calculated using (1) and (2). Low PI values indicate high temperature susceptibility. In this study PI is calculated using penetration values of 15 and $25^{\circ} \mathrm{C}$. In this study the PI system has been used to give a good 
approximation of the behaviour of bitumen to be expected, but its confirmation has been done by using viscosity measurements.

\section{Penetration-Viscosity Number (PVN)}

The penetration-viscosity (Mcleod 1972) number is another measure used to determine the temperature susceptibility of bitumens. This number is based on penetration at $25^{\circ} \mathrm{C}$ and viscosity at $60^{\circ} \mathrm{C}$, using Equation 3.

$\mathrm{PVN}=\frac{6.491-1.5 \log P_{25}-\log \eta_{60}}{1.05-0.22 \log P_{25}}(-1.5)$

Where: $\mathrm{P}_{25}$ is penetration at $25^{\circ} \mathrm{C}$ and $\eta_{60}$ is viscosity at $60^{\circ} \mathrm{C}$.

\section{Viscosity Temperature Susceptibility (VTS)}

The viscosity temperature susceptibility (VTS) value for measuring temperature susceptibility for any particular bitumen sample was determined using Equation 4:

$\mathrm{VTS}=\frac{\left(\log \left(\log \eta_{1}\right)\right)-\left(\log \left(\log \eta_{2}\right)\right)}{\log T_{1}-\log T_{2}}$

Where: $\eta_{1}$ is the viscosity at $T_{1}$ and $\eta_{2}$ is the viscosity at $\mathrm{T}_{2}$. $\mathrm{T}_{1}$ and $\mathrm{T}_{2}$ in this study are $100^{\circ} \mathrm{C}$ and $135^{\circ} \mathrm{C}$ respectively.

\section{FTIR analysis}

Fourier transform infrared spectroscopy (FTIR) analysis was used for identification and quantification of functional groups present in bitumen. FTIR spectra were collected for binders using a Bruker-Alpha FTIR spectrometer equipped with a zincselenide $(\mathrm{ZnSe})$ series and attenuated total reflectance (ATR). Bitumen samples were placed directly on the ZnSe window, and the spectra were obtained. Forty scans at a resolution of $0.8 \mathrm{~cm}^{-1}$ were taken for each sample, and background scans were between wave numbers 3000 to $500 \mathrm{~cm}^{-1}$. The resultant spectra were corrected using both ATR and baseline correction functions in the OPUS software.

\section{Table 4 Viscosity ratio of bitumen}

\begin{tabular}{|l|l|l|}
\hline \multirow{2}{*}{ Bitumen } & \multicolumn{2}{|c|}{ Viscosity ratio } \\
\cline { 2 - 3 } & RTFOT aged & PAV aged \\
\hline LGB & 2.3 & 4.0 \\
\hline VG 10 & 1.9 & 3.5 \\
\hline VG 30 & 1.5 & 3.0 \\
\hline
\end{tabular}

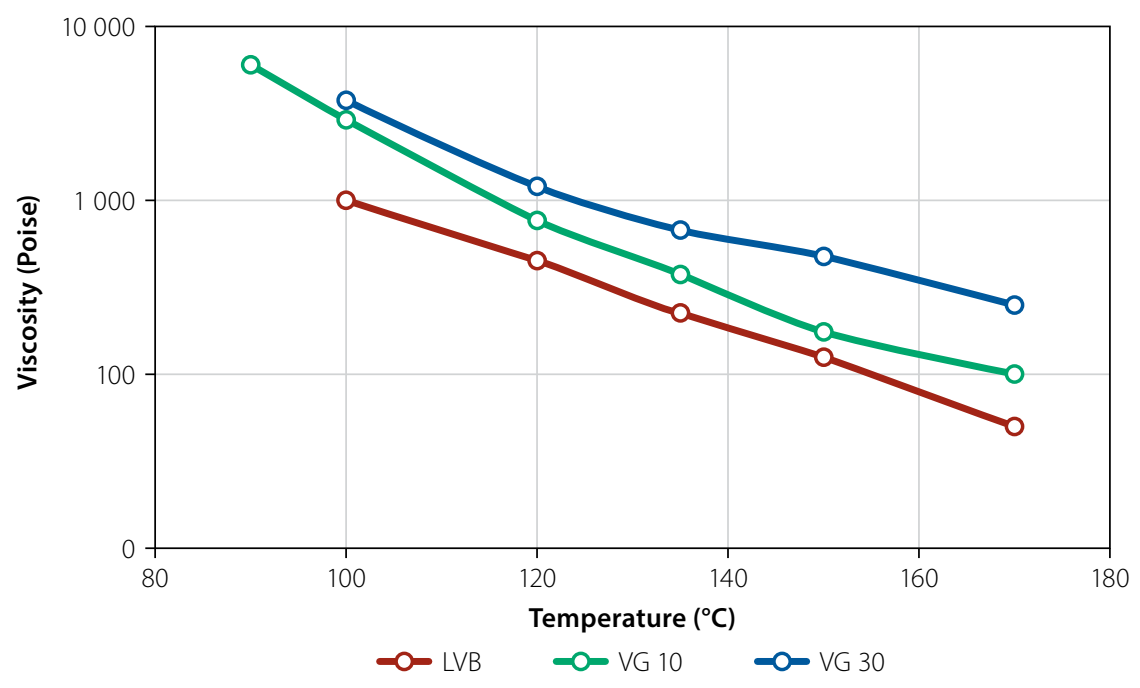

Figure 4 Viscosity temperature relationship of bitumen

\section{Foaming procedure}

A bitumen foaming process was undertaken in the laboratory pilot plant to determine the optimum foaming water content and optimal foaming temperature according to the following test operational conditions:

- Air pressure: $550 \mathrm{kPa}$

- Water pressure: $600 \mathrm{kPa}$

- Temperature of bitumen: $120^{\circ} \mathrm{C}, 130^{\circ} \mathrm{C}$, $140^{\circ} \mathrm{C}, 160^{\circ} \mathrm{C}$ and $180^{\circ} \mathrm{C}$

Water content: $2 \%, 4 \%, 6 \%, 8 \%, 10 \%$ and $11 \%$

- Amount of bitumen being foamed during each test: $500 \mathrm{gm}$ at the rate of $50 \mathrm{gm} / \mathrm{sec}$.

\section{Sample preparation and \\ strength characterisation}

To check the effective binding of foam using LGB in the mix, foam mix samples, termed as bitumen stabilised mix (BSM), were cast with three different foam binder contents (varying from 1.8 to $2.2 \%$ at an increment of $0.2 \%$ with $80 \%$ of recycled aggregate). In this study, BSM Level 1 mix design was carried out for all binders (LGB, VG 10 and VG 30) as per TG2 guidelines (Asphalt Academy 2002; 2009). The tensile properties of BSM were evaluated using indirect tensile strength (ITS).
Six specimens were compacted, of which three were used to determine ITS under unconditioned conditions and the rest were tested after proper conditioning. After proper curing, the unconditioned specimens were tested for ITS at $25^{\circ} \mathrm{C}$. For conditioning, the specimens were placed in a water bath at $40^{\circ} \mathrm{C}$ for 24 hours and then placed in an environmental chamber maintained at $25^{\circ} \mathrm{C}$ for two hours. Using failure load, and specimen dimensions, dry and wet ITS were calculated for unconditioned and conditioned samples, respectively using Equation 5.

$\sigma_{t}=\frac{2 \mathrm{P}}{\pi \mathrm{Dt}}$

Where:

$\mathrm{P}=$ maximum load,

$\mathrm{D}=$ diameter of the specimen, and

$\mathrm{t}=$ thickness of the specimen.

\section{RESULTS AND DISCUSSION}

\section{Properties of bitumen}

The relationship between the viscosity values of the different bitumen samples selected for foaming at different temperatures are presented in Figure 4. The viscosity
Table 5 Complex modulus values before and after RTFOT ageing of bitumen

\begin{tabular}{|c|c|c|c|}
\hline \multirow{2}{*}{ Bitumen } & \multicolumn{2}{|c|}{ Complex modulus (G*) (kPa) } & \multirow{2}{*}{$\begin{array}{c}\text { Complex } \\
\text { Modulus Ratio }\end{array}$} \\
\hline & Un-aged & RTFOT aged & \\
\hline LGB & 7.2 & 20.4 & 2.83 \\
\hline VG 10 & 23.3 & 38.9 & 1.67 \\
\hline VG 30 & 31.4 & 52.3 & 1.66 \\
\hline
\end{tabular}


ratio (ageing index) of the bitumen after the RTFOT and PAV ageing tests are given in Table 4. Results show that the viscosity ratio of LGB is higher than VG 10 and VG 30 indicating more stiffness after ageing. Due to the presence of BEO, it is more prone to oxidation compared to VG 10 and VG 30. $\mathrm{G}^{*}$ values at $45^{\circ} \mathrm{C}$ at $1.5 \mathrm{~Hz}$ before and after short-term ageing are given in

Table 5. The complex shear modulus ratio shows similar results to the viscosity ratio. The G* value of un-aged LGB is $7.2 \mathrm{kPa}$, which increases to $20.4 \mathrm{kPa}$ after shortterm ageing, which is nearly equal to the $G^{*}$ value of un-aged VG 10 bitumen. It may be concluded that after short-term ageing the low grade bitumen can behave as VG 10 during the mix performance.

\section{Foaming characteristics with respect to expansion ratio and half-life}

Expansion ratio (ER) and half-life (HL) were determined for all binders at different foaming temperatures $\left(120^{\circ} \mathrm{C}, 130^{\circ} \mathrm{C}\right.$, $140^{\circ} \mathrm{C}, 160^{\circ} \mathrm{C}$ and $180^{\circ} \mathrm{C}$ ) and different water contents $(2 \%, 4 \%, 6 \%, 8 \%, 10 \%$ and $11 \%)$. HL was determined as the time in seconds that the foam required to collapse from maximum expansion to half of expansion. Figure 5 shows the foaming properties of the different bitumen types, expressed in mean values of three replicates. It is observed that with increasing viscosity of bitumen, the HL increases and a higher temperature is needed for a better foaming process. The results indicate that LGB can produce better foam at $120^{\circ} \mathrm{C}$ compared to VG 10 and VG 30, whereas it will also require less energy. In Table 1 the minimum requirements of ER and $\mathrm{HL}$ for acceptable foam were summarised and compared to the global scenario; the bitumen used in this study shows higher halflife and expansion ratio, which may be due to the addition of higher water content.

\section{Optimisation of water content and temperature}

The water content in the foaming process is optimised for each temperature and is given in Table 6. Optimum water content is determined where the HL and ER curves meet, showing optimum ER and HL values (Figure 5) (Xiao et al 2011; Raffaelli 2004). From the results it is observed that, with increasing temperature of the foaming process, the water required to obtain the maximum half-life and expansion ratio decreases. For example, at $120^{\circ} \mathrm{C}$, the
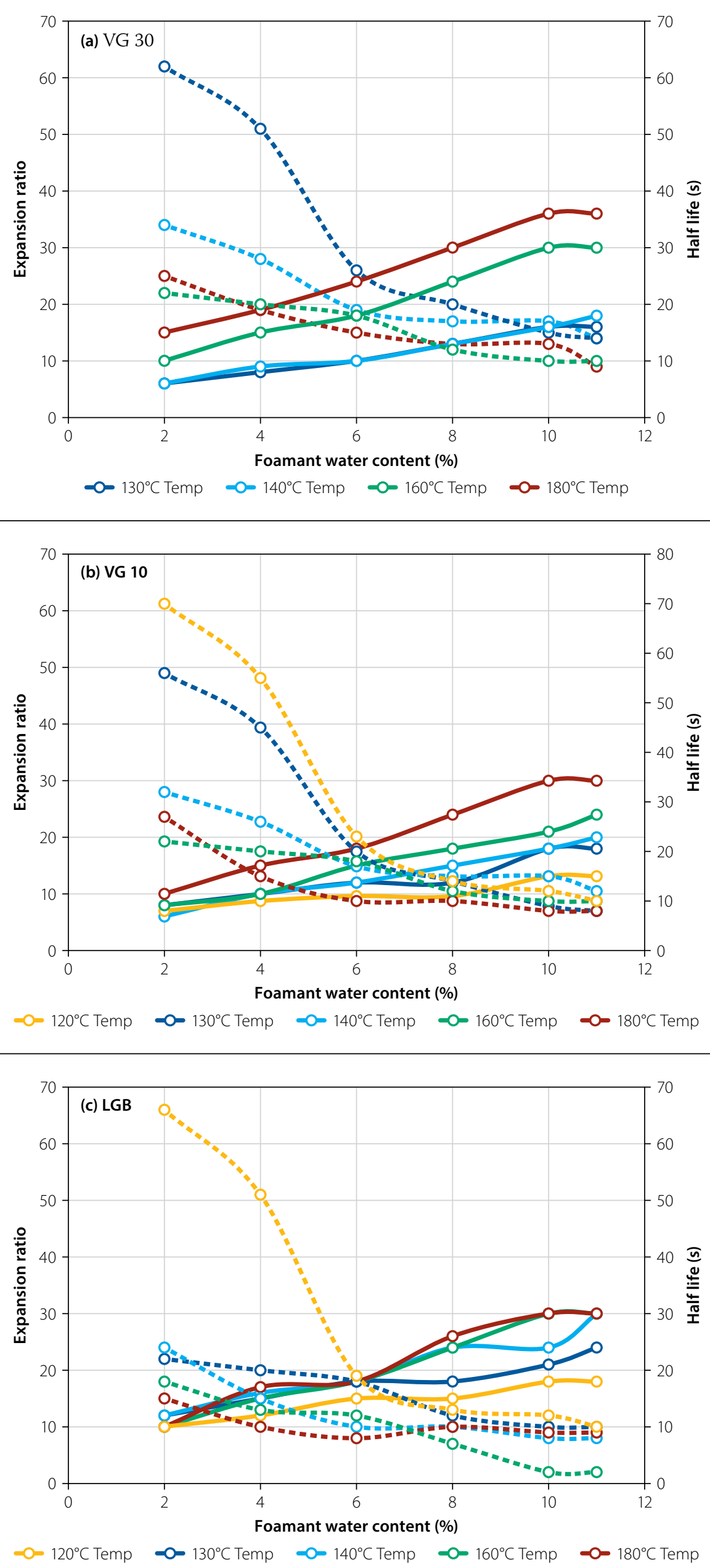

Figure 5 Foaming characteristics of different bitumen types 
Table 6 Optimisation of water content and temperature

\begin{tabular}{|c|c|c|c|c|}
\hline Bitumen & $\begin{array}{c}\text { Temperature } \\
\left({ }^{\circ} \mathrm{C}\right)\end{array}$ & $\begin{array}{c}\text { Water } \\
\text { content (\%) }\end{array}$ & $\begin{array}{l}\text { ER } \\
(\%)\end{array}$ & $\begin{array}{c}\text { HL } \\
\text { (sec) }\end{array}$ \\
\hline \multirow{5}{*}{ LGB } & 120 & 7 & 15 & 15 \\
\hline & 130 & 6 & 18 & 18 \\
\hline & 140 & 4 & 15 & 15 \\
\hline & 160 & 4 & 12 & 12 \\
\hline & 180 & 2.5 & 12 & 12 \\
\hline \multirow{5}{*}{ VG 10} & 120 & 9 & 11 & 11 \\
\hline & 130 & 8.5 & 15 & 15 \\
\hline & 140 & 8 & 15 & 15 \\
\hline & 160 & 6.5 & 14 & 14 \\
\hline & 180 & 4.5 & 14 & 14 \\
\hline \multirow{5}{*}{ VG 30} & 120 & - & - & - \\
\hline & 130 & 10 & 16 & 16 \\
\hline & 140 & 10 & 18 & 18 \\
\hline & 160 & 6 & 19 & 19 \\
\hline & 180 & 3 & 18 & 18 \\
\hline
\end{tabular}

similar values for all binders when RTFO is done at optimum binder temperature for foaming. After foaming, the foamed sample is kept still for two hours and water is removed by pouring out; the remaining bitumen is subjected for testing and termed as foamed binder. The viscosity ratio of foam shown in Figure 6 is defined as the ratio of viscosity of virgin binder to the viscosity of foamed binder and is closer to unity, showing a negligible difference in the viscosity of binders before and after foaming.

\section{Rheological properties of bitumen and effect on foaming characteristics}

Figure 7 shows the isochronal plots for the different bitumen binders used in this work. From these plots it is observed that, as the frequency increases, the shear complex modulus $\left(\mathrm{G}^{*}\right)$ also increases.

Furthermore, it is also found that the shear complex modulus decreases with increase in temperature. expansion ratio and half-life are 11 and 15 for both VG 10 and LGB respectively, whereas for VG 30 at the same temperature, foaming is not obtained. For VG 30, the maximum $\mathrm{ER}$ and $\mathrm{HL}$ is $160^{\circ} \mathrm{C}$.

\section{Ageing characteristics of bitumen and the effect on foaming characteristics} Ageing of bitumen occurs during mixing, placement and compaction, as well as during the service life of the road. To simulate the ageing process under short-term and long-term conditions, RTFO ageing and PAV ageing were carried out. The viscosity ratio was determined for identification of the oxidation behaviour of the binder. The viscosity ratio was calculated for RTFO aged at $163^{\circ} \mathrm{C}$, RTFO aged at optimum foaming temperature PAV aged, and foamed binder. The viscosity based ageing ratio was calculated using Equation 5. The computed viscosity ageing ratio (VR) for all binders are presented in Figure 6.

The lower temperatures for RTFO were selected in accordance with the temperatures at which the foaming of different binders is optimised, as shown in Table 6. Since foam mix and HMA are subjected to similar conditions in the field, the PAV ageing conditions were not altered and were kept the same for both foam and HMA binders. The viscosity ageing ratio shows that LGB is more prone to ageing when compared to VG 10 and VG 30 through the RTFOT and PAV test. However, ageing indices show

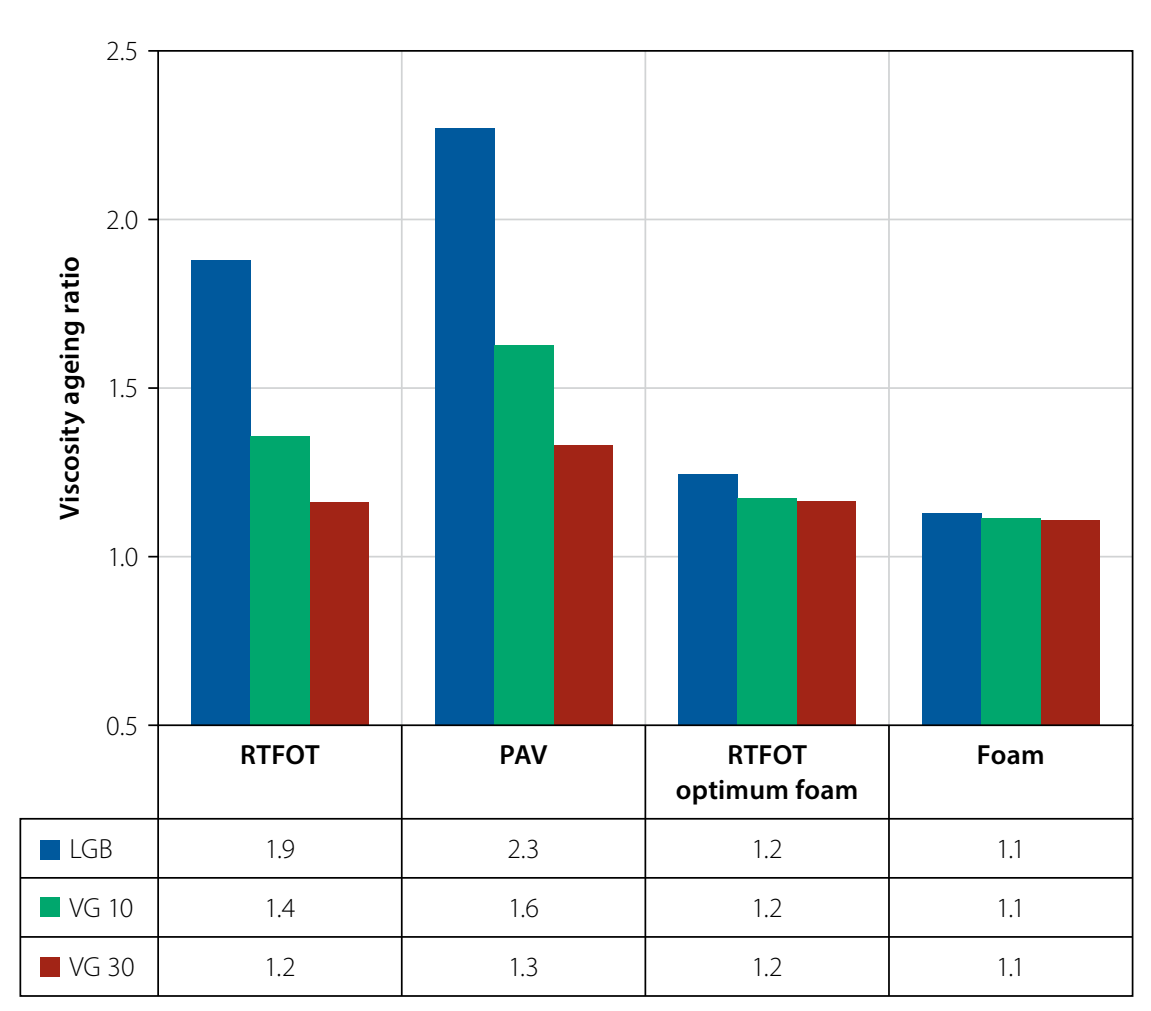

Figure 6 Viscosity ratio of aged, un-aged and foam binders

Table 7 Complex modulus and phase angle values of bitumen

\begin{tabular}{|c|c|c|c|c|c|c|c|c|}
\hline Temperature & \multicolumn{2}{|c|}{$15^{\circ} \mathrm{C}$} & \multicolumn{2}{|c|}{$45^{\circ} \mathrm{C}$} & \multicolumn{2}{|c|}{$90^{\circ} \mathrm{C}$} & \multicolumn{2}{|c|}{$120^{\circ} \mathrm{C}$} \\
\hline Bitumen types & $\begin{array}{c}\mathbf{G}^{*} \\
(\mathrm{kPa})\end{array}$ & $\delta, 0$ & $\begin{array}{c}\mathbf{G}^{*} \\
(\mathrm{kPa})\end{array}$ & $\delta,{ }^{0}$ & $\begin{array}{c}\mathbf{G}^{*} \\
(\mathrm{kPa})\end{array}$ & $\delta, 0$ & $\begin{array}{c}\mathbf{G}^{*} \\
(\mathrm{kPa})\end{array}$ & $\delta, 0$ \\
\hline LGB & 241 & 74.0 & 7.2 & 84.0 & 0.06 & 90.0 & 0.007 & 89.9 \\
\hline VG 10 & 1770 & 61.0 & 23.3 & 80.4 & 0.14 & 88.9 & 0.009 & 89.7 \\
\hline VG 30 & 2460 & 63.0 & 31.4 & 81.8 & 0.12 & 89.1 & 0.01 & 89.3 \\
\hline
\end{tabular}



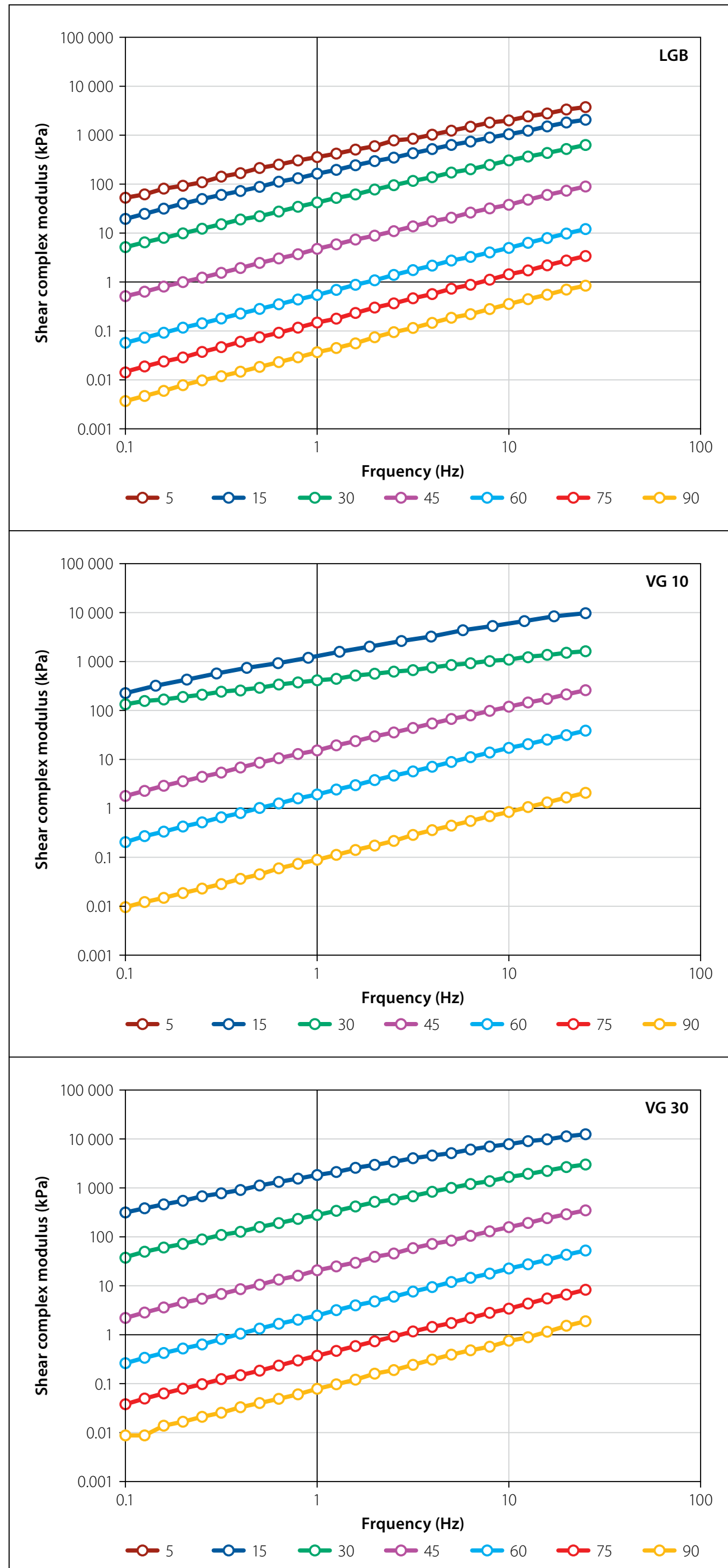

Figure 7 Isochronal plots for different bitumen types at various temperatures $\left({ }^{\circ} \mathrm{C}\right)$
Table 7 presents the results of $G^{*}$ and phase angle $(\delta)$ with varying temperatures for different bitumen types. It was observed that at temperature $45^{\circ} \mathrm{C}$, the bitumen types LGB, VG 10 and VG 30 experience $\mathrm{G}^{*}$ in increasing order, whereas the phase angle $(\delta)$ is not substantially different. The substantial difference was observed at low temperatures only. Results indicate that LGB demonstrates more viscous behaviour compared to VG 10 and VG 30, showing a higher phase angle at lower temperatures. At $120^{\circ} \mathrm{C}$ there is no substantial difference in the $G^{*}$ and $\delta$ values for all three types of bitumen. Hence, complex modulus and phase angle do not have much effect on foaming characteristics.

It can be seen that all three types of bitumen behave as sol between $45^{\circ} \mathrm{C}$ to $120^{\circ} \mathrm{C}$, as phase angle values are high and comparable, but there is considerable difference in phase angle values at $15^{\circ} \mathrm{C}$, which indicate more elastic behaviour of VG 10 and VG 30 compared to LGB bitumen. BBR was used to evaluate low temperature properties of PAV aged binders. Creep stiffness and $\mathrm{m}$-value were obtained from this testing procedure. The BBR test was conducted at different temperatures, i.e. $-14^{\circ} \mathrm{C},-18^{\circ} \mathrm{C},-20^{\circ} \mathrm{C},-22^{\circ} \mathrm{C},-24^{\circ} \mathrm{C}$ and $-28^{\circ} \mathrm{C}$. Figures $8(\mathrm{a})$ and (b) show the stiffness and $\mathrm{m}$-value for all binders at different temperatures, respectively. As per the Asphalt Institute's Superpave Series No 1 (SP 1), the creep stiffness of specified grade temperature should be less than or equal to $300 \mathrm{MPa}$ at $60 \mathrm{~s}$, with an m-value greater than or equal to 0.3 at $60 \mathrm{~s}$. Hence, the low cracking of LGB, VG 10 and VG 30 has been determined to be $-20,-18$ and $-14^{\circ} \mathrm{C}$, respectively. Therefore, $\mathrm{LGB}$ is likely to demonstrate better resistance to cracking at low temperature. Due to the sol behaviour of LGB at lower temperatures, it may show better coating during mixing with aggregates.

\section{Temperature susceptibility of bitumen and its effect on foaming}

Due to the sudden change of bitumen temperature upon its contact with cold water in the foaming process, the temperature susceptibility might have an effect on the foamability and the quality of the produced foam. Therefore three approaches were used to evaluate and characterise this property - penetration index (PI), penetration-viscosity number (PVN) and viscosity temperature susceptibility (VTS) (Roberts et al 1991). Low PI, low PVN, 


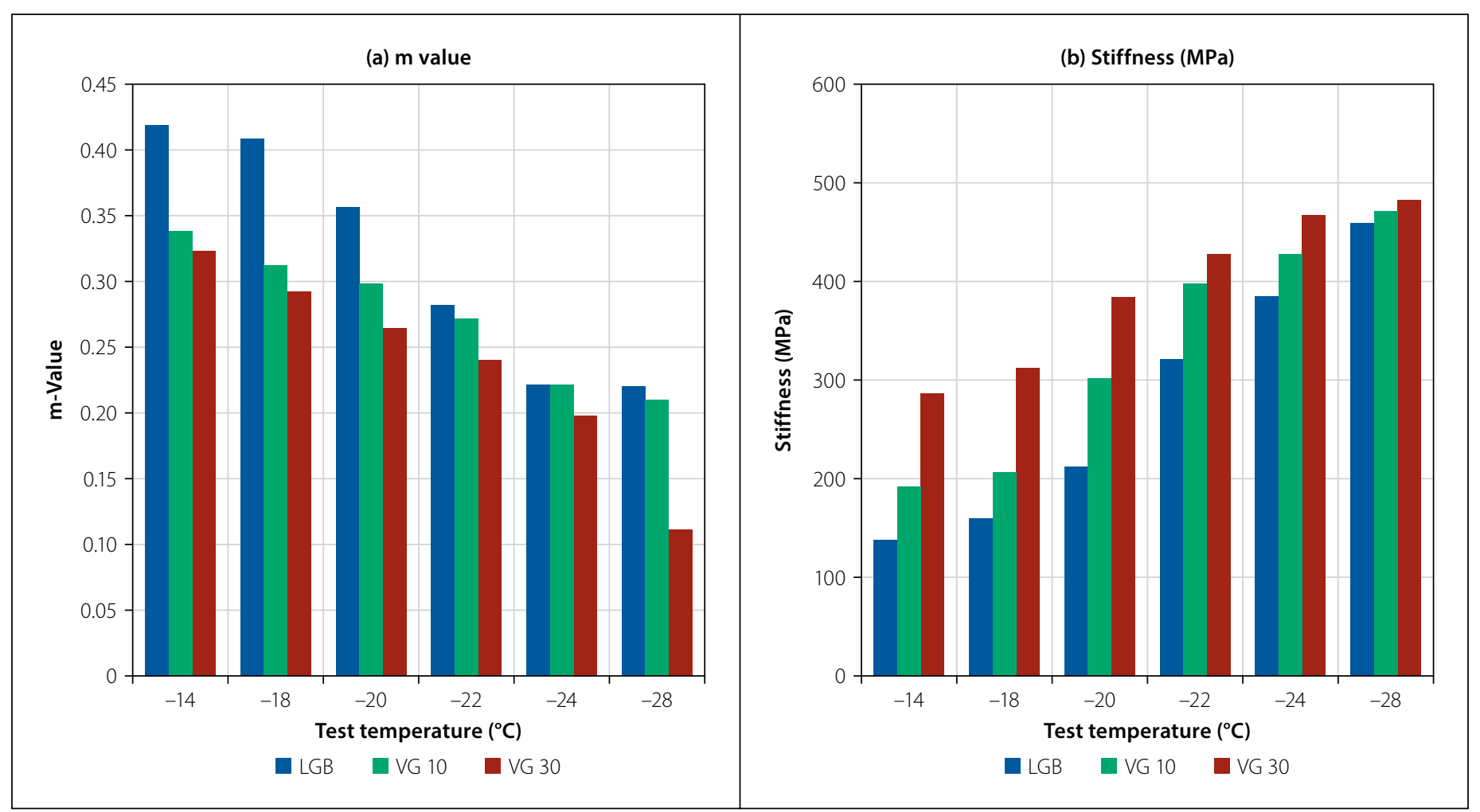

Figure 8 BBR results for low temperature cracking

and high VTS values are indicators of a bitumen that is highly susceptible to temperature changes, and vice versa indicates that the bitumen has lower temperature susceptibility. Variations of PI, PVN and VTS with respect to different grades of bitumen are presented in Figures 9(a),

(b) and (c) respectively. Figure 9(a) shows that the PI values are between -1.41 and -1.81 . According to Roberts et al (1991), PI values for most good paving bitumen types are between +1 and -1 . High temperature susceptibility occurs when the bitumen has a PI less than -2. LGB shows the lowest PI value while VG 30 exhibits the highest PI in the range of 15 to $25^{\circ} \mathrm{C}$.
Figure 9(b) shows that all PVN values were between 3.65 and 0.57. According to Roberts et al (1991) most paving bitumen types have a PVN between 0.5 and -2.0. Bitumen class VG 30 showed the lowest PVN value, while LGB exhibited the highest. Thus, VG 30 is the most temperature-susceptible bitumen and LGB is the least temperature-susceptible bitumen. Therefore, LGB exhibits the highest resistance to cracking at a low temperature range compared to VG 30 and VG 10. Figure 8(c) shows that all VTS values are between 3.69 and 2.92. LGB bitumen shows the highest value, while VG 30 exhibits the lowest. Thus, LGB is the most temperature-susceptible bitumen at the temperature range of $100^{\circ} \mathrm{C}$ to $135^{\circ} \mathrm{C}$.

Foaming of bitumen is done at higher temperature ranges, i.e $120^{\circ} \mathrm{C}$ to $180^{\circ} \mathrm{C}$. At $120^{\circ} \mathrm{C}$, VG 30 could not produce acceptable foam. Hence, it can be correlated that, due to high temperature-susceptibility, LGB shows better foaming characteristics at $120^{\circ} \mathrm{C}$ compared to VG 10 and VG 30. This is due to a decrease in viscosity of LGB at $120^{\circ} \mathrm{C}$, compared to VG 10 and VG 30 showing better foaming at lower temperatures.

It is obvious that VG 30 is the most temperature-susceptible bitumen according to the results obtained from PI and

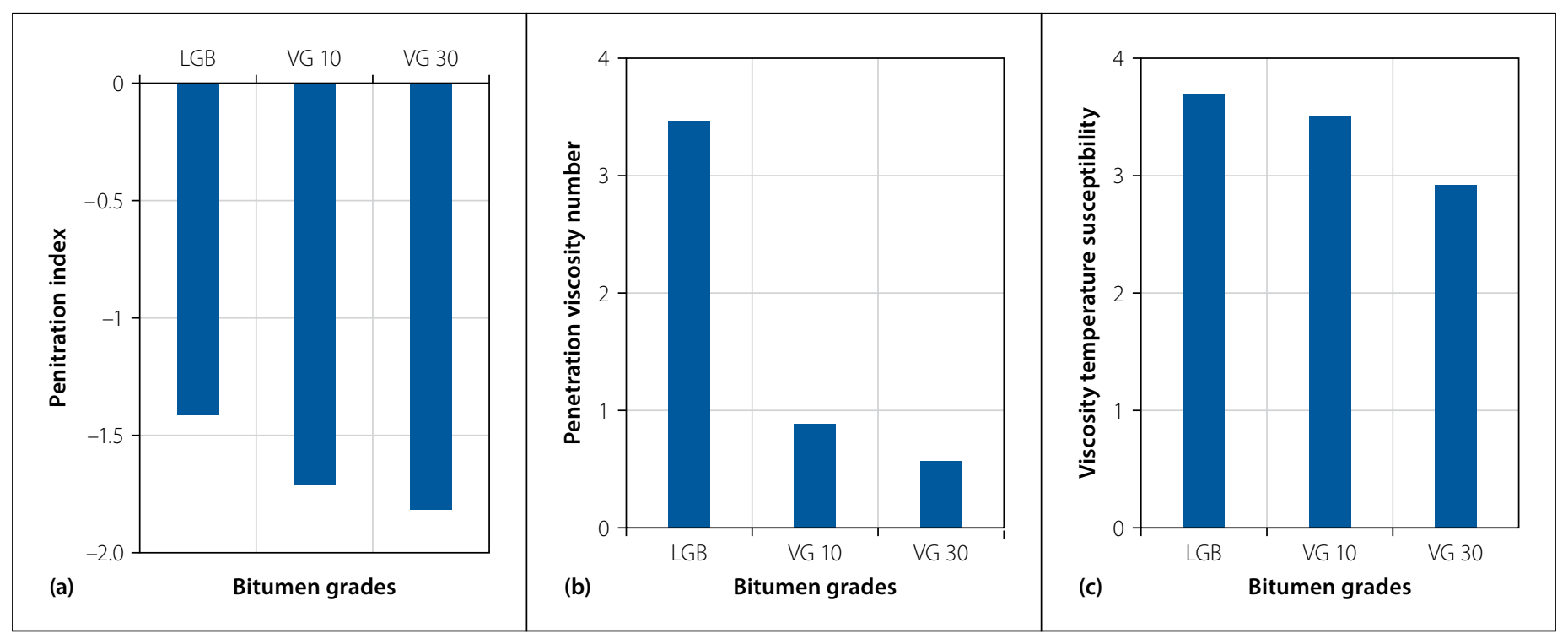

Figure 9 Temperature-susceptibility of bitumen 


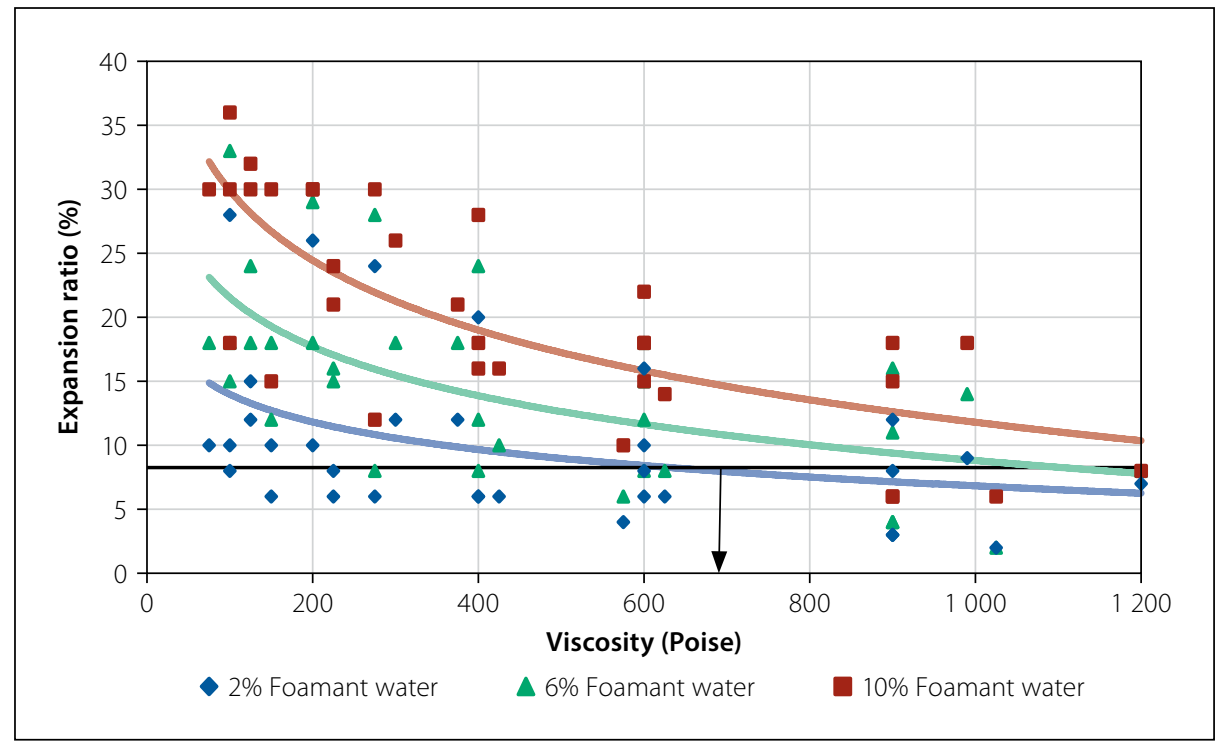

Figure 10 Effect of viscosity on expansion ratio

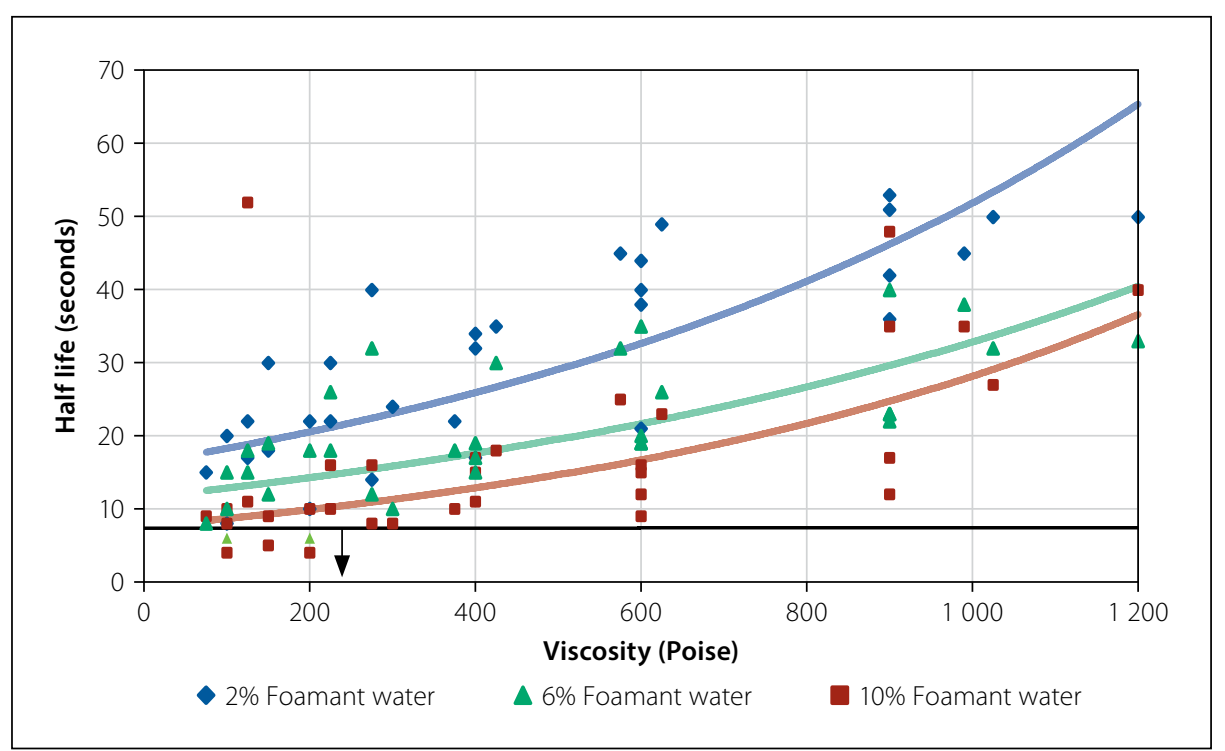

Figure 11 Effect of viscosity on half-life

PVN, and produces unacceptable foam at lower temperature. VG 10, which is also comparatively less temperature-susceptible, shows reasonable foaming characteristics similar to those produced by LGB (which is the least temperature-susceptible bitumen). The conclusion is that the use of temperature-susceptible bitumen types at temperatures below $120^{\circ} \mathrm{C}$ does not have a direct effect on the foaming properties. Many literature studies are available supporting such results (Saleh 2007; Iwánski et al 2015; Roberts 1991; Pengcheng \& John 2007).

\section{Effect of viscosity of bitumen on foaming characteristics}

To check the effect of viscosity on ER and $\mathrm{HL}$, numerical values of ER and HL were plotted against viscosity. Plots of ER vs viscosity, and HL vs viscosity are presented in Figures 10 and 11, tabulated in Table 8.
$\mathrm{ER}=\mathrm{A} \times \ln (\eta)+\mathrm{B}$

$\mathrm{HL}=\mathrm{A} \ln e^{B \times \eta}$

Where: $A$ and $B$ are coefficients, and $\eta$ is the viscosity of bitumen at foaming temperature.

In general, ER vs viscosity, and HL vs viscosity exhibited negative exponential and logarithmic trends, respectively. The correlation coefficient was lower than 0.6 for all cases. As specified by TG2 (Asphalt Academy 2009), the minimum criteria of ER and HL are chosen to be 8 and $6 \mathrm{~s}$. Figure 10 shows that for an expansion ratio greater than or equal to 8 , viscosity must be lower than 700 Poise at foaming temperature. Similarly, it can be concluded from Figure 11 that viscosity must be greater than 250 Poise for half-life greater than or equal to $6 \mathrm{~s}$. Hence, the optimum range of viscosity for acceptable foaming characteristics was found to be between 250 and 700 Poise. A bitumen having viscosity less than 250 Poise shows better expansion ratio, but foam is unstable due to a lower half-life. It is a well-known fact that the viscosity of bitumen decreases with increase in temperature, and subsequently the thinning effect of the bitumen film of bubbles leads to reduced HL. Similar observations on reduced HL with lower viscosity have been made by other researchers (Saleh 2007; Wirtgen 2004).

\section{Effect of chemical composition on foaming characteristics}

The foaming effects on binder chemical composition using Fourier transform infrared spectroscopy and X-Ray radiography techniques have been investigated by various authors (Namutebi et al 2011; Hailesilassie et al 2015), but the effect of binder structure on foaming has not been studied yet. Figure 12 shows the sulphoxide, carbonyl, aromatics and aliphatic
Table 8 Coefficient and $R^{2}$ values

\begin{tabular}{|c|c|c|c|c|}
\hline \multirow{2}{*}{ Equation no } & $\begin{array}{c}\text { Foaming water } \\
\text { content (\%) }\end{array}$ & $\mathbf{A}$ & $\mathbf{B}$ & \multirow{2}{*}{$\mathbf{R}^{\mathbf{2}}$} \\
\hline \multirow{2}{*}{5.1} & 10 & -7.8 & 66.1 & 0.56 \\
\hline & 6 & -5.5 & 46.9 & 0.37 \\
\hline & 2 & -3.1 & 28.2 & 0.15 \\
\hline & 10 & 7.6 & 0.001 & 0.42 \\
\hline & 6 & 11.6 & 0.001 & 0.46 \\
\hline
\end{tabular}




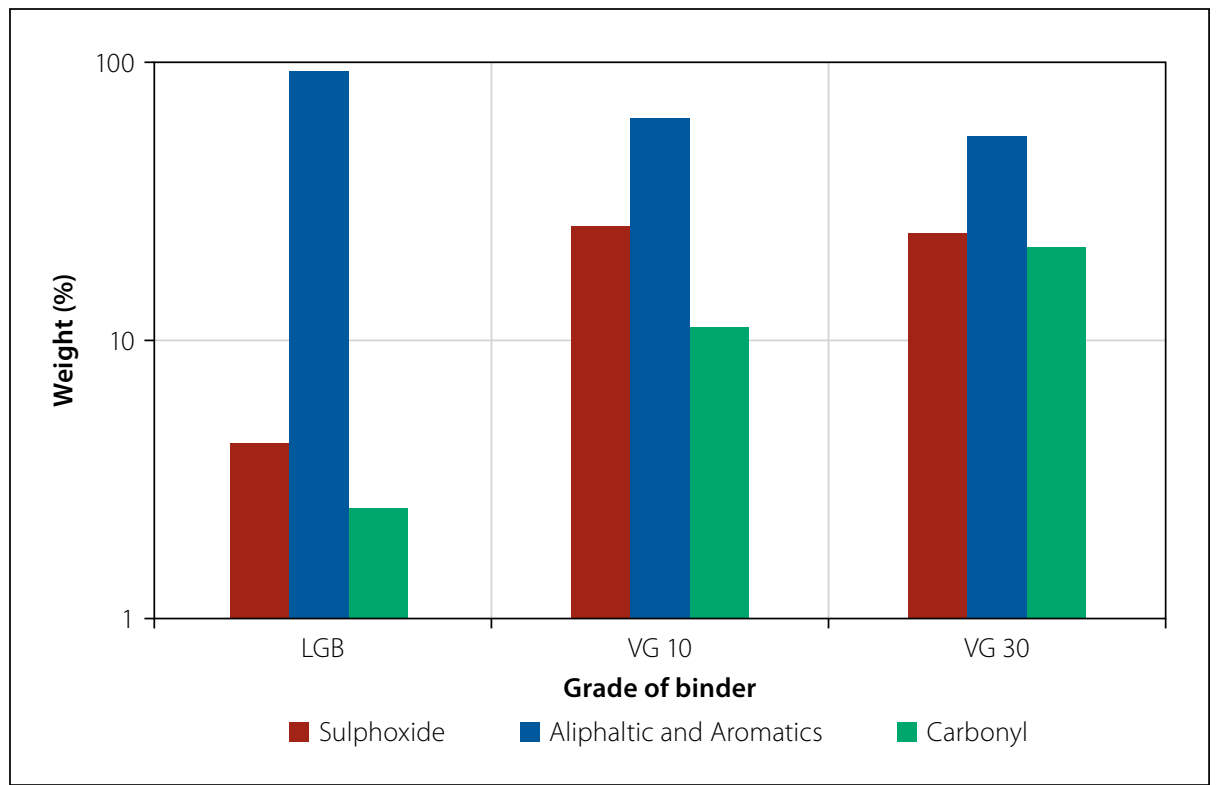

Figure 12 Carbonyl, sulphoxide, aromatics and aliphatic fractions of bitumen

fraction of all the binders. Asphaltene contains some nitrogen, sulphur and oxygen in addition to carbon and hydrogen. Sulphoxide and carbonyl content increases with increase in asphaltene content, hence results in an increase in the viscosity of the binder. Within the bitumen fluid system, sulphoxide and carbonyl components act as surfactants (Hung et al 2012). Surfactants, sulphoxide and carbonyl reduce the surface tension in the surface of the bubbles and hence collapse of the foam is delayed. For the same reason, a decrease in ER was observed with increasing sulphoxide and carbonyl content. It can be correlated that with an increase in carbonyl and sulphoxide compound, the expansion ratio decreases and half-life increases.

\section{Strength characteristics of BSM}

The optimum moisture content (OMC) of this untreated blend was found to be $6.2 \%$ by using the moisture-density relationships according to AASHTO T180 specifications. Figures 13(a) and (b) show the variation of dry ITS and wet ITS, respectively, with respect to binder quantity and type. For a particular foamed bitumen content, a higher ITS value was observed with mixtures prepared with a higher viscosity grade. This can be attributed to the higher stiffness provided by the bitumen. A mix prepared with LGB gives more than the required
ITS values in both dry and wet conditions (dry ITS $>225 \mathrm{kPa}$ and wet ITS $>100 \mathrm{kPa}$ ), which show the effective binding properties of LGB in mix design consideration.

\section{CONCLUSION}

There is an increasing trend worldwide to use foamed bitumen. Most of the studies reporting on foamed bitumen have focused on the effect of water content and bitumen temperature during foaming. The conclusions drawn from the laboratory study are as follows:

1. The temperature susceptibilities of the different types of bitumen were investigated using VTS, PVN and PI. According to PVN and PI, VG 30 is most temperature-susceptible in the temperature range $15^{\circ} \mathrm{C}$ to $60^{\circ} \mathrm{C}$ compared to VG 10 and LGB. But at higher temperatures, LGB shows the highest temperature-susceptibility. Use of temperature-susceptible bitumen at temperatures below $100^{\circ} \mathrm{C}$ does not have a direct effect on the foaming properties. LGB is the least temperature-susceptible bitumen. Therefore LGB exhibits the highest resistance to cracking at a low temperature range compared to VG 30 and VG 10.

2. Foaming is done above $120^{\circ} \mathrm{C}$. At $120^{\circ} \mathrm{C}$ and higher temperatures there is no substantial difference in the values of $G^{*}$ and $\delta$ for all six binders. Hence, complex modulus and phase angles have little effect on foaming characteristics.

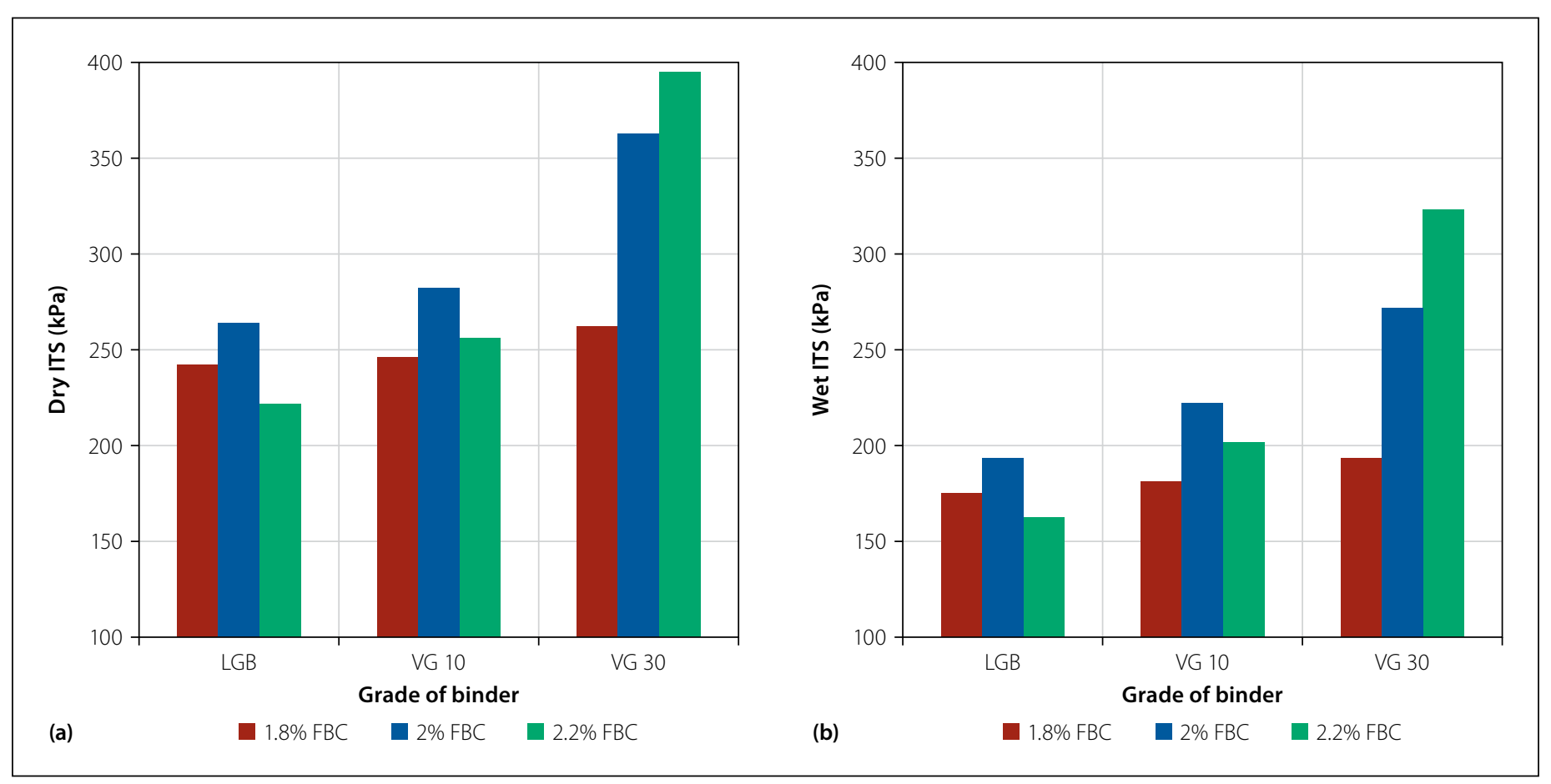

Figure 13 Variation of (a) dry ITS, and (b) wet ITS with binder type and quantity 
3. From various tests and analyses it has been found that foaming characteristics depend on the viscosity of bitumen, along with the foaming temperature and foamant water content.

4. The performance of foamed bitumen depends not only on the rheology of bitumen, but also on the chemical composition of bitumen. From FTIR results it has been concluded that, with an increase in carbonyl and sulphoxide compound, the expansion ratio decreases and half-life increases, due to decrease in surface tension of the binder.

5. Viscosity of bitumen is an important factor. Foaming temperature may be decided on the basis of viscosity value. The optimum range of viscosity for acceptable foaming characteristics is found to be between 250 and 800 Poise.

6. LGB consumes low energy during the foaming process compared to high viscosity bitumen. If LGB is used in place of VG 30 bitumen for foaming technology, foam can be produced at $40^{\circ} \mathrm{C}$ lower, which can result in a huge saving on energy consumption and greenhouse gas emissions.

\section{ACKNOWLEDGEMENTS}

The authors are thankful to the Director, CSIR-Central Road Research Institute, New Delhi 110025, for permission to publish this paper. The authors would also like to thank Shri Satish Pandey (Scientist, CSIR-Central Road Research Institute) and Ms Writgen for their support during the installation of the WLBS 10 Foaming Plant.

\section{REFERENCES}

Abel, F \& Hines, C R 1979. Base stabilization with foamed asphalt. Interim Report FHWA-CORD-79-5. Denver, CO: Colorado Division of Highways.

Airey, G D 2002. Rheological evaluation of ethylene vinyl acetate polymer modified bitumens. Construction and Building Materials, 16: 473-487. Asphalt Academy 2002. Bitumen stabilised materials, 1st ed. Asphalt Academy Interim Technical Guideline TG2. Pretoria: Asphalt Academy.

Asphalt Academy 2009. Bitumen stabilised materials. A guide for the design and construction of bitumen emulsion and foamed bitumen stabilised materials, 2nd ed. Asphalt Academy Technical Guideline TG2. Pretoria: Asphalt Academy.

Austroads 2006. Deformation resistance of asphalt mixtures by the wheel tracking test. Test Method AGPT/T23. Sydney, New South Wales: Austroads.
Barinov, E N 1990. Formation and properties of bituminous foams. Chemistry and Technology of Fuels and Oils, 26(10): 544-548.

Bowering, R H \& Martin, C L 1976. Foamed bitumen production and application of mixtures, evaluation and performance of pavements. Proceedings of the Association of Asphalt Paving Technologists, 45: 453-477.

Brennen, M, Tia, M, Altschaeffl, A G \& Wood, LE 1983. Laboratory investigation of the use of foamed asphalt for recycled bituminous pavements. Transportation Research Record, 911: 80-87. Crispino, M, Giustozzi, F, Martinez-Arguelles, G \& Toraldo, E 2014. Effects of foam agents on foaming processes and physical and rheological properties of bitumens. Proceedings, 3rd International Conference on Transportation Infrastructure, Pisa, Italy, 22-25 April, p 147.

Csanyi, L H 1960. Bituminous mixes prepared with foamed asphalt. Iowa Engineering. Experiment Station Bulletin No. 189. Ames, IO: Iowa State University of Science and Technology.

Hailesilassie, B W, Hugener, M, Bieder, A \& Partl, M N 2015. New experimental methods for characterizing formation and decay of foamed bitumen. Materials and Structures, 49(6): 2439-2454.

He, G P \& Wong, W G 2006. Decay properties of the foamed bitumens. Construction and Building Materials, 20(10): 866-877.

Hung, A M, Goodwin, A \& Fini, E H 2012. Effects of water exposure on bitumen surface microstructure. Construction and Building Materials, 135: 682-688.

IS (Indian Standard) 2013. IS: 73. Paving Bitumen - Specification. New Delhi: Bureau of Indian Standards.

Iwánski, M \& Chomicz-Kowalska, A 2012. Moisture and frost resistance of the recycled base rehabilitated with the foamed bitumen technology. Archives of Civil Engineering, 58(2): 185-198.

Iwánski, M, Chomicz-Kowalska, A \& Maciejewski, K 2015. Application of synthetic wax for improvement of foamed bitumen parameters. Construction and Building Materials, 83: 62-69.

Jenkins, K J 2000. Characterisation of foamed bitumen. Chapter 3. Mix design considerations for cold and half-warm bituminous mixes with emphasis on foamed bitumen. PhD Thesis, University of Stellenbosch.

Jenkins, K J, Van de Ven, M F C \& De Groot, J L A 1999. Characterisation of foamed bitumen. Proceedings, 7th Conference on Asphalt Pavements for Southern Africa, 1-18.

Jenkins, K J \& Van de Ven, M F C 2001. Guidelines for the mix design and performance prediction of foamed bitumen mixes. Proceedings, 20th Southern African Transport Conference, 16-20 July, Pretoria, Session 1A:7, pp 1-12.

Kendall, M, Baker, B, Evans, P \& Ramanujam, J 1999.

Foamed bitumen stabilisation Proceedings, Southern Region Symposium on Roads at Work - Developing
Southern Queensland, 21 October, Goondiwindi, Queensland, Australia.

Lancaster, J, McArthur, L \& Warwick, R 1994. VICROADS experience with foamed bitumen stabilisation. Proceedings, 17th ARRB Conference, 15-19 August, Gold Coast, Queensland, Vol 17, Part 3, pp 193-211.

Lesueur, D, Clech, H, Brosseaud, A, Such, C, Cazaclin, B, Koenders, B, Cérino, P J \& Bonvallet, J 2004. Foamability and foam stability. Road Materials and Pavement Design, 5(3): 277-302.

Maccarrone, S, Holleran, G, Leonard, D J \& Hey, S 1994. Pavement recycling using foamed bitumen. Proceedings, 17th ARRB Conference, Gold Coast, Queensland, 15-19 August, Vol 17, Part 3.

Martinez-Arguelles, G, Giustozzi, F, Crispino, M \& Flintsch, G W 2015. Laboratory investigation on mechanical performance of cold foamed bitumen mixes: Bitumen source, foaming additive, fiberreinforcement and cement effect. Construction and Building Materials, 93: 241-248.

Martinez-Arguelles, G, Giustozzi, F, Crispino, M \& Flintsch, G W 2017. Investigating physical and rheological properties of foamed bitumen. Construction and Building Materials, 72: 423-433.

Mcleod, N W 1972. A four-year survey of low temperature transverse pavement cracking on three Ontario test roads. Proceedings of the Association of Asphalt Paving Technologists, 41: 424-493.

Middleton, B \& Forfylow, R 2009. Evaluation of warm-mix asphalt produced with the double barrel green process. Transportation Research Record, 2126: 19-26.

Morton, B S 2001. The foamability of tar and engineering properties of foamed tar mixes. MEng Dissertation, University of Pretoria.

Morton, B S, Visser, A T \& Horak, E 2002. The application of foamed tar technology to labour intensive construction of low volume roads. Proceedings, 21st Southern African Transport Conference, 15-19 July, Pretoria.

Morton, B S, Visser, A T \& Horak, E 2003. Investigation of the foamability of tar and the characterisation and optimisation of foamed tar. International Journal of Pavement Materials and Design, 3(4): 385-401.

Morton, B S, Visser, A T \& Horak, E 2004. Foamed tar stabilization: State of the art review and pavement performance incorporating new accelerated pavement testing method, Proceedings, 8th Conference on Asphalt Pavements for Southern Africa, 12-16 September, Sun City, South Africa. Namutebi, M, Birgisson, B \& Bagampadde, U 2011. Foaming effects on binder chemistry and aggregate coatability using foamed bitumen. Road Materials and Pavement Design, 12(4): 821-847.

Nivedya, M K, Roja, K L, Veeraragavan, A \& Krishnan, J M 2013. Rheological investigations on foamed bitumen. Proceedings, Airfield and Highway Pavements Conference, Sustainable and Efficient 
Pavements, ASCE, 9-12 June, Los Angeles, CA, pp 967-976.

Pengcheng, F \& John, T H 2007. Temperature sensitivity of foamed asphalt mix stiffness: field, and lab study. International Journal of Pavement Engineering, 8(2): 137-145.

Raffaelli, D 2004. Foamed asphalt base stabilization. Technical Topics series. Berkley, CA: University of California Berkley, Institute of Transportation Studies.

Roberts, F L, Kandhal, P S, Brown, E R \& Lee, D Y 1991. Hot mix asphalt materials, mixture design and construction. Lanham, MD: Napa Valley Education Foundation.

Ruckel, P J, Acott, S M \& Bowering, R H 1983. Foamed-asphalt paving mixtures: Preparation of design mixes and treatment of test specimens. Transportation Research Record, 911: 88-95.

Saleh, M F 2007. Effect of rheology on the bitumen foamability and mechanical properties of foam bitumen stabilized mixes. International Journal of Pavement Engineering, 8(2): 99-110.

Sunarjono, S 2008. The influence of foamed bitumen characteristics on cold-mix asphalt properties. $\mathrm{PhD}$ Thesis. Nottingham, UK: University of Nottingham, Transportation Engineering Centre, School of Civil Engineering.

Van der Poel, C 1954. A general system describing the visco-elastic properties of bitumens and its relation to routine test data. Journal of Applied Chemistry, 4: 221-236.
Wahhab, H I A A, Baig, M G, Mahmoud, I A \& Kattan, H M 2012. Study of road bases construction in Saudi Arabia using foam asphalt. Construction and Building Materials, 26(1): 113-121.

Wirtgen, F 2004. Cold Recycling Manual. Wirtgen GmbH: Windhagen, Germany.

Xiao, F, Punith, V S, Putman, B \& Amirkhanian, S N 2011. Utilization of foaming technology in warm-mix-asphalt mixtures containing moist aggregates. Journal of Materials in Civil Engineering, 23(9): 1328-1337.

Xiao, F, Newton, D, Putman, B, Punith, V S \& Amirkhanian, S N 2013. A long-term ultraviolet aging procedure on foamed WMA mixtures. Materials and Structures, 46(12): 1987-2001. 